\title{
Semi-Truck Team Driver Pinned and Killed while Adjusting Tandems
}

\section{Incident Number: 14KY064}

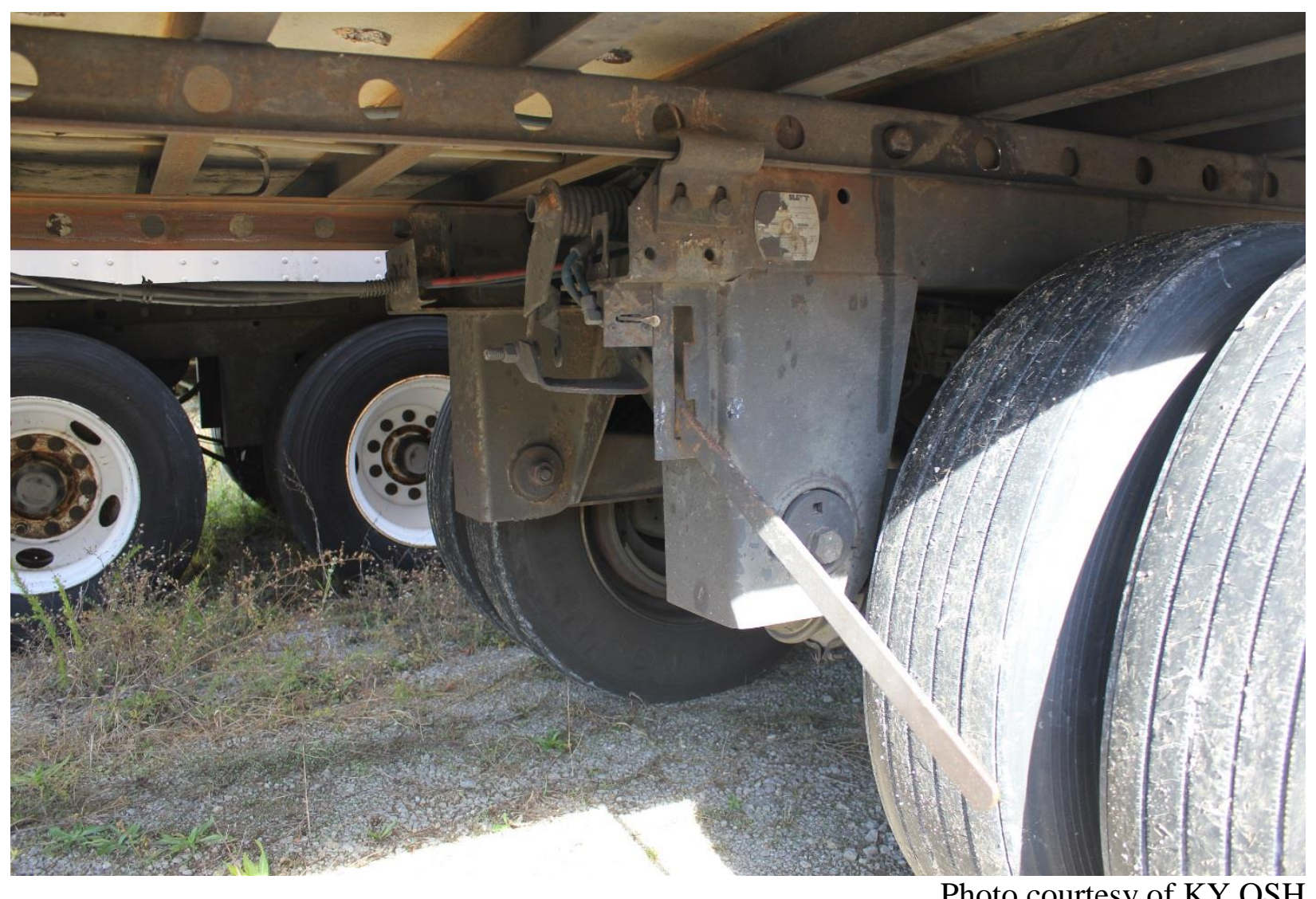

Photo courtesy of KY OSH

Kentucky Fatality Assessment and Control Evaluation Program Kentucky Injury Prevention and Research Center 333 Waller Avenue

Suite 242

Lexington, Kentucky 40504

Phone: 859-323-2981

Fax: 859-257-3909

www.kiprc.uky.edu

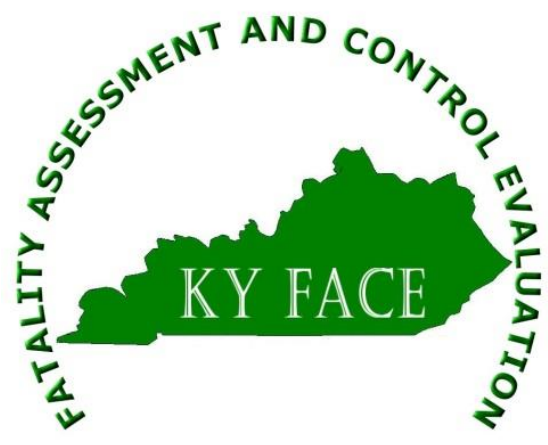




\section{Kentucky Fatality Assessment and Control Evaluation (FACE) Program Incident Number: 14KY064 \\ Release Date: September 2, 2015 \\ Subject: Semi Truck Team Driver Pinned and Killed while Adjusting Tandems}

\section{Introduction}

On October 30, 2014, at approximately 7:00 am, a semi-truck driver and fellow team driver parked in a chain restaurant parking lot to make their delivery, unloaded their product, and were adjusting the tandems on the trailer. The team driver placed himself near the tandems while the semi-truck driver climbed into the truck cab to rock the truck so that the tandems would slide into place. The team driver was found with his head pinned between the tire and the bottom of the trailer.

To prevent future occurrences of similar incidents, the following recommendations have been made:

Recommendation No. 1: Employers should consider providing tools such as extension rods, to allow workers to remain clear of moving or shifting parts.

Recommendation No. 2: Tandem adjustments should be performed by a single driver.

Recommendation No. 3: Drivers should consider using a tandem stopper tool.

\section{$\underline{\text { Employer }}$}

The employer was an out-of-state family business and parent company to a leading food service distributor. The company delivers food and food related products to more than 150,000 independent and national chain restaurants, quick service eateries, pizzerias, theaters, schools, hotels, healthcare facilities and other institutions. The employer was established in 1987 and employs 320 employees.

\section{Written Safety Programs and Training}

The employer provided written safety programs and annually updated training records for each employee. It is unknown whether specific training was provided on tandem adjustment. The driver was an on-the-job trainee.

$\underline{\text { Victim }}$

The victim was 59-year-old father of two children. His career as a truck driver spanned 40 years, with no recorded accidents or injuries. 


\section{$\underline{\text { Tandems }}$}

According to the FMCSA, the standard allowable weight for a regular 5-axle truck and semitrailer on the interstate is $12,000 \mathrm{lbs}$. for the steering axles, 34,000 lbs. for the drive axles and $34,000 \mathrm{lbs}$. for the trailer tandem equaling $80,000 \mathrm{lbs}$. of acceptable weight.

Sliding tandems are necessary and required for three main reasons:

- To adjust weight off the tractor's rear axles to the trailer tandem axles;

- To adjust weight off the trailer tandem axles and move some of the weight forward to the tractor's rear;

- To set the vehicle's axle spacing to meet state requirements you are operating in.

When the tandem slides forward more weight rests on the trailer tandems and weight shifts from the tractor's drive axles. Sliding the tandems backwards removes weight from the trailer tandems and shifts weight to the drive axles. This is necessary and done often to balance the weight on a trailer and prevent a truck from being overweight.

Trailer tandems lock into place with a set of locking pins that slide into holes drilled into the tandem slide rail. The hole spacing distance varies between trailer manufacturers but the larger the distance between holes, the more weight will be shifted as the tandem slides from hole to hole. There are usually two hole spacing widths, 4 inches or 6 inches; 4 -inch spacing calculates into 250 lbs. per hole whereas 6-inch spacing calculates into 400lbs per hole. The weight calculation determines how tandems should be spaced.

\section{Incident Scene}

The incident took place in the parking lot of a food chain restaurant, on a flat, smooth surface void of any inclines. The trailer was a Great Dane, manufactured in 1999. It was approximately 58 feet 10 inches long by 10 feet wide. The release handle for the tandem axle was mechanical, and required manual action to disengage and lock it into place. Release instructions were visible on a placard at the side of the trailer, about mid-length.

\section{$\underline{\text { Weather }}$}

On October 30, 2014, there were scattered clouds with temperatures ranging from 41 to 43 degrees Fahrenheit. Weather was not considered a factor in this fatality.

\section{$\underline{\text { Investigation }}$}

The Kentucky Fatality Assessment and Control Evaluation Program was notified by KY OSHA of an occupational fatality involving a semi-truck driver.

On October 30, 2014, at approximately 7:00 am, a semi-truck driver and his team driver parked in a chain restaurant parking lot to deliver frozen food, and adjust the load on the truck. The team 
driver sprayed WD-40 onto the pins then struck them with a hammer in an attempt to loosen the rust that caused the pins to stick. When the pins were loose, he actuated a manual release lever near the front of the tandem and instructed the semi-truck driver to rock the truck back and forth to release the tandems (see photos \#1 \& \#3).

The semi-truck driver set the brake on the trailer and after he received an audible signal from the victim, he got into the cab of the truck and rocked the trailer back and forth to move the tandem. The team driver who was standing beside the trailer informed the semi-truck driver that the technique did not work. The semi-truck driver then reset the brake on the tractor with the intent to exit the cab, when he heard a loud bang and felt the trailer move. The semi-truck driver exited, and noticed the victim's head pinned between the tire and the bottom of the trailer (see photo \#2). The semi-truck driver ran to the team driver victim and received no response. He then ran to the restaurant for additional help. One restaurant employee called Emergency Management Services (EMS) while another employee returned with the driver to assist the victim.

When they reached the victim, they discovered he had fallen to the ground, and was no longer trapped. The restaurant employee noticed that the victim's head was bleeding, removed his own shirt and placed it around the victim's head. The driver and restaurant employee also noticed blood coming out of the victim's mouth and rolled him onto his right side as he struggled for breath. EMS was notified at 8:45 am and arrived on scene at 8:49 am to discover a police officer performing CPR on the victim. EMS took over and called Air Transport. Air Transport was cancelled after EMS pronounced the co-pilot deceased at the scene at 9:20 am. The victim was then transported to a local hospital to wait for the coroner.

\section{Cause of Death}

The cause of death was massive head trauma from a crush injury.

\section{$\underline{\text { Recommendations and Discussions }}$}

Recommendation No. 1: Employers should consider providing extension rods to manually adjust tandems that will allow workers to remain clear of moving or shifting tandems. ${ }^{1}$

Extension rods can pull the release latch and prevent drivers from having to position themselves between the tires and tandems. The extension rod also helps protect drivers' shoulders from rotator cuff injuries.

\section{Recommendation No. 2: Tandem adjustments should be performed by the semi-truck driver.}

Employers should consider the implementation of a best practice where only the semi-truck driver adjusts the tandems. This prevents miscommunication between two drivers and eliminates placing one of the drivers in a hazardous situation.

\section{Recommendation No. 3: Drivers should consider using a tandem stopper tool. ${ }^{3}$}


Many drivers use a tandem stopper tool which makes it easier for the semi-truck driver to adjust the tandems thereby eliminating the need for a second driver to assist.

\section{$\underline{\text { Keywords }}$}

Trucking

Tandems

Safety

\section{$\underline{\text { References }}$}

${ }^{1}$ Tips for sliding tandems. Keeping Trucking Safe.

[http://www.KeepTruckingSafe.org/]

${ }^{2}$ How to slide your tandems. Youtube

[https://www.youtube.com/watch?v=o1TXQeljhvI]

\section{Acknowledgements}

The Kentucky FACE program would like to thank the KY OSH and Kentucky Trucking Association KTA for their assistance with this report.

The Kentucky Fatality Assessment \& Control Evaluation Program (FACE) is funded by grant 2U60OH008483-10 from the Centers for Disease Control and Prevention and the National Institute for Occupational Safety and Health. The purpose of FACE is to aid in the research and prevention of occupational fatalities by evaluating events leading to, during, and after a work related fatality. Recommendations are made to help employers and employees have a safer work environment. For more information about FACE and KIPRC, please visit our website: www.mc.uky.edu/kiprc/projects/KOSHS/index.html 


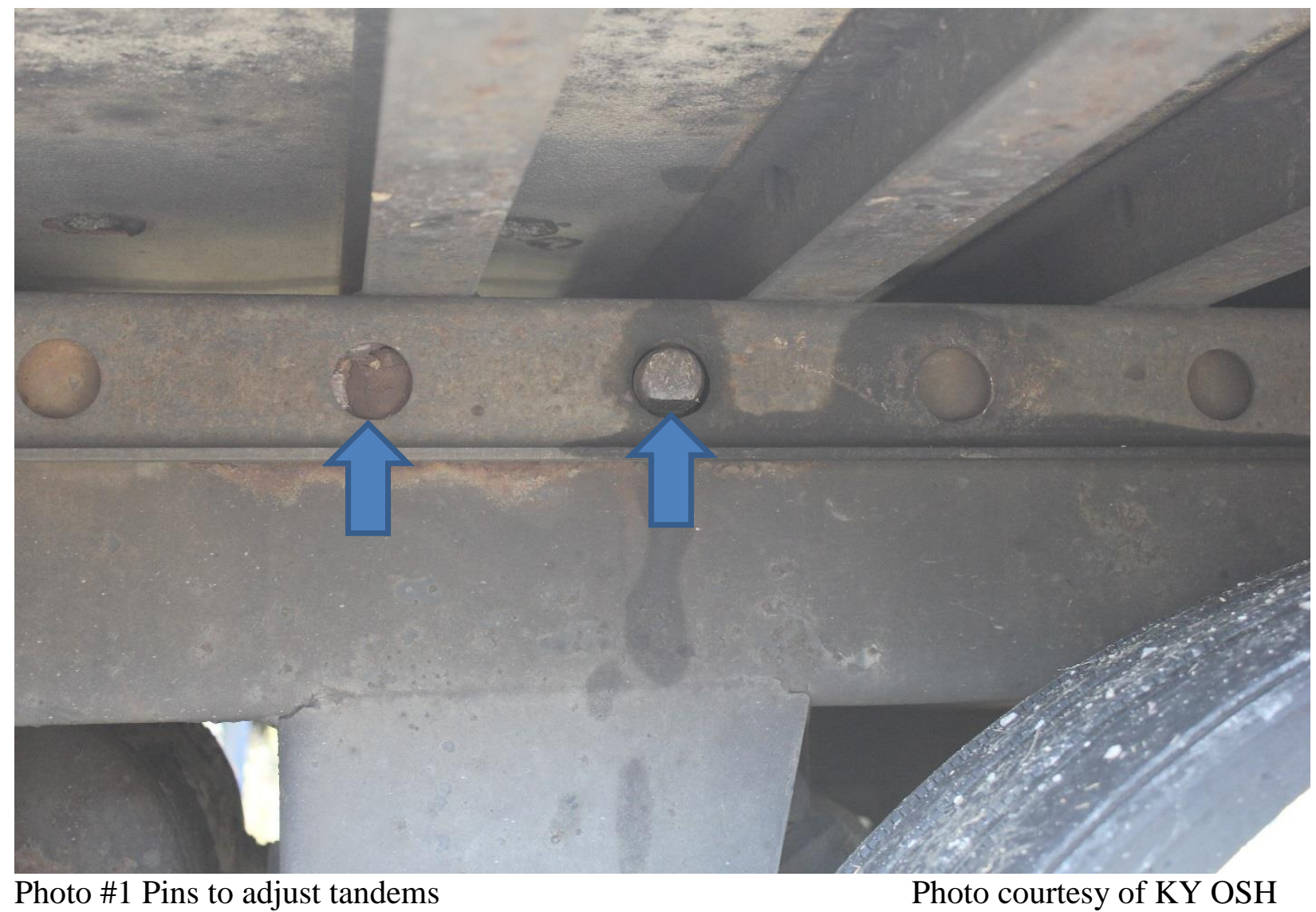




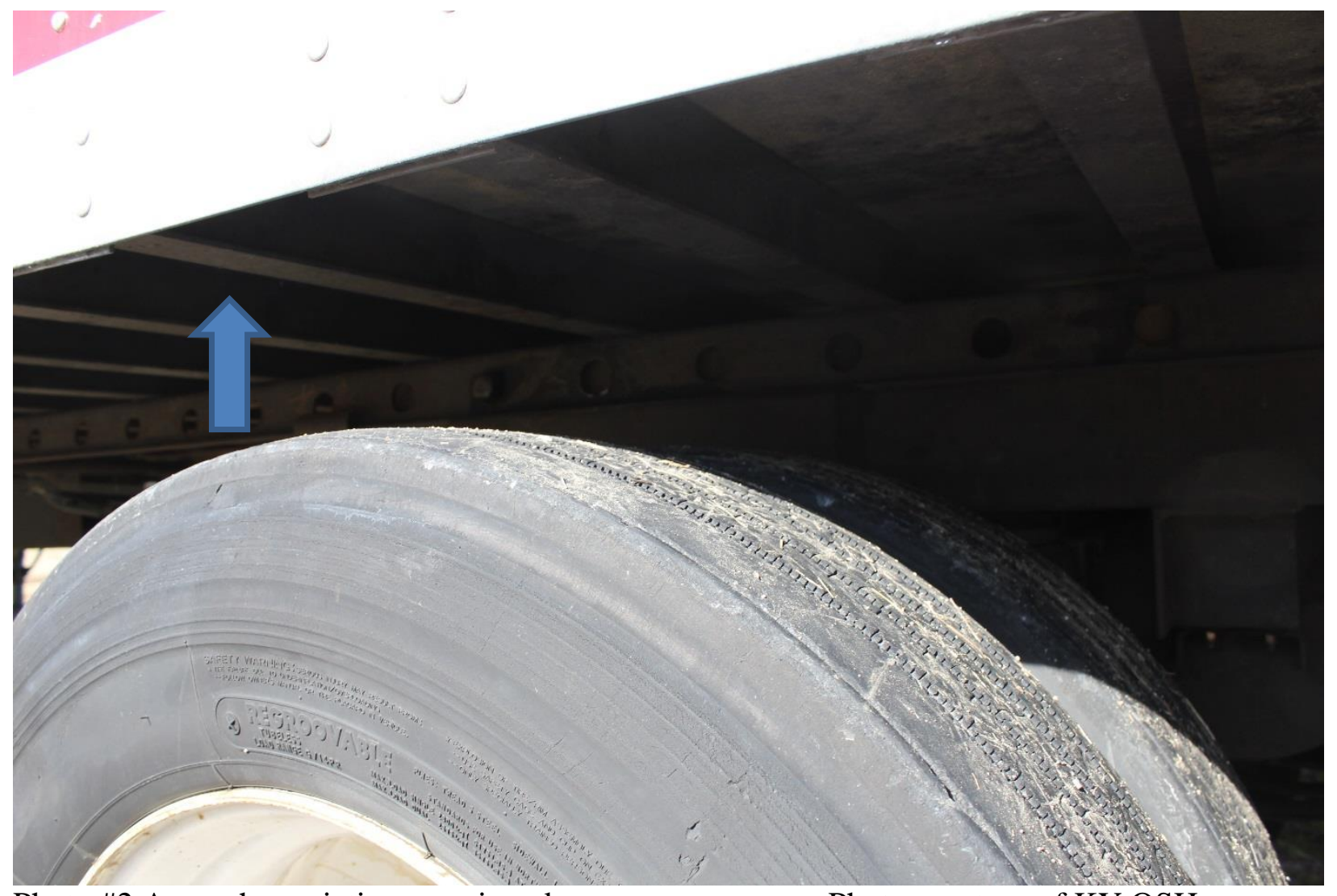

Photo \#2 Area where victim was pinned

Photo courtesy of KY OSH 


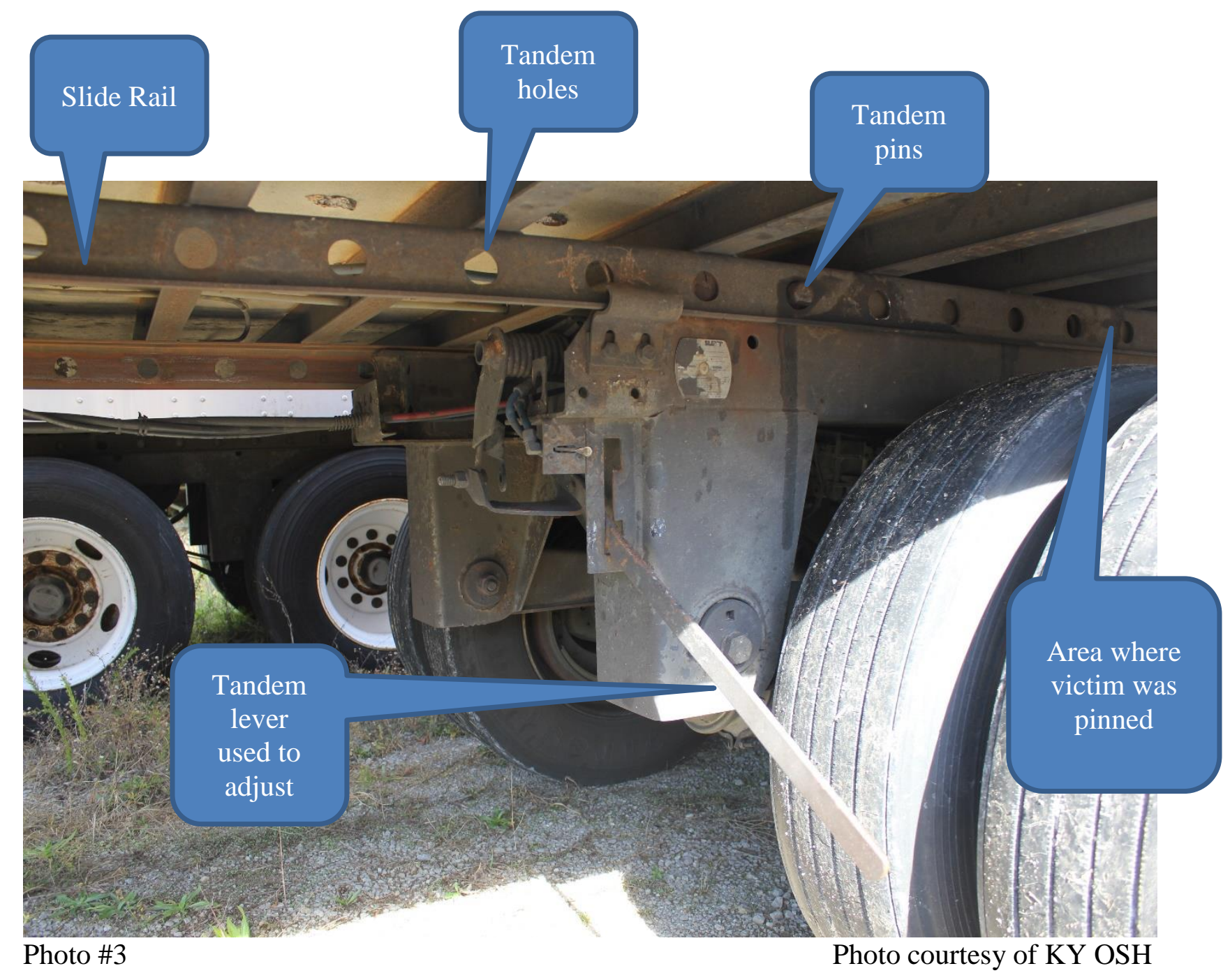

